\section{AL LLEGAR: PRIMEROS PASOS DE LA PEREGRINA EN ESPAÑA}

\author{
Luisa Campuzano \\ Programa de Estudios de la Mujer, \\ Casa de las Américas, La Habana \\ Icampuzano@cubarte.cult.cu
}

Cómo citar este artículo/Citation: Campuzano, L. (2014). "Al llegar: primeros pasos de La Peregrina en España". Arbor, 190 (770): a180. doi: http://dx.doi.org/10.3989/ arbor.2014.770n6001

Recibido: 12 febrero 2014. Aceptado: 30 octubre 2014.

RESUMEN: Este artículo se propone analizar, desde la perspectiva de los estudios sobre las diásporas, la literatura de viajes, las llamadas "escrituras del yo", y los estudios de género, las Memorias y la Autobiografía de Gertrudis Gómez de Avellaneda, textos privados, no destinados a la prensa, publicados a comienzos del siglo XX. En ambos, con diferentes intenciones y procedimientos, la criolla joven e ilustrada describe y califica crudamente a la Galicia pre-moderna en la que se ve obligada a vivir entre 1836 y 1838; y compara sus ciudades, costumbres, prejuicios y, en particular, la situación, régimen de vida y trabajo de sus mujeres, con los que ha conocido y practicado en Cuba. Su estatuto de expatriada y su enfrentamiento con un espacio de acogida hostil aguzarán determinados rasgos de su personalidad y determinarán la elección de su pseudónimo: La Peregrina.

PALABRAS CLAVE: Gertrudis Gómez de Avellaneda, Memorias, Autobiografía, expatriación, espacio de acogida, Galicia 18361838 , mujeres.

\section{ON ARRIVAL: THE FIRST STEPS OF LA PEREGRINA IN SPAIN}

Copyright: (C) 2014 CSIC. Este es un artículo de acceso abierto distribuido bajo los términos de la licencia Creative Commons Attribution-Non Commercial (by-nc) Spain 3.0.
ABSTRACT: The aim of this paper is to analyse, from the perspective of diasporic studies, travel writing, memoirs and autobiographical writing and gender studies, Gertrudis Gómez de Avellaneda's Memorias and Autobiografía, both personal texts, not meant to published in the press, but later published in the early 20th century. In both of them, with different aims and approaches, the young and "Enlightened" creole, sharply describes and names the premodern Galicia where she had to live between 1836 and 1838; comparing its cities, customs, prejudices and, in particular, the position of women, their life and work routine, with those she had known and experienced in Cuba. Her expatriate status and her conflict with an unwelcoming environment, would help shape some of her personality traits and her choice of pseudonym: La Peregrina.

KEYWORDS: Gertrudis Gómez de Avellaneda, memoirs, autobiography, expatriation, reception space, Galicia 18361838, women. 
1.

El primer texto conocido de Avellaneda, su soneto "Al partir", escrito en el barco que la llevó en la primavera de 1836 a Europa, así como las Memorias que escribiera a fines del 38 para su prima Heloysa, y la Autobiografía que destinara siete meses después a Ignacio de Cepeda, muestran -aun pasando por alto convenciones literarias, lecturas de la autora y estrategias a las que me referiré más adelante- la cicatriz de su separación de la Isla, cuya violencia resuena en un verso del primero de estos textos: "para arrancarme del nativo suelo" (Avellaneda, 1869, I, p. 1). Debe tenerse en cuenta que "arrancar [...] de raíz", "separar a alguien del lugar o medio donde se ha criado" son, según el DRAE, dos acepciones de "desarraigar".

También debo explicar que no por gusto elijo el término "cicatriz", sino porque esta locución y su empleo metafórico se ubican en un campo semántico trillado hace más de dos décadas por distintos estudiosos de los desplazamientos humanos, como Gloria Anzaldúa: "la frontera es siempre una herida abierta" (Anzaldúa, 1987, p. 3); Stuart Hall: "la emigración es un gesto definitivo"; (Hall, 1987, p. 44); Edward Said: "el exilio es una muerte simbólica." (Said, 1984, p. 160). Campo semántico orientado por las concepciones de Freud sobre el duelo y la melancolía, consideradas por él como reacciones "ante la pérdida de un ser querido o de una abstracción [...], como la patria [...]". El duelo, sigo con Freud, puede ser superado con el tiempo. Pero cuando no se supera el dolor de la pérdida, cuando no se elabora el duelo, los sentimientos de pena y de tristeza se vuelven contra quien los experimenta, colocándolo en un estado melancólico que erosiona todas sus relaciones con el mundo exterior, y puede llevarlo a la concentración narcisista en su autoconocimiento... (Freud, 1915/1976, XIV, p. 241).

Retengo esta última frase: "concentración narcisista en su autoconocimiento", porque no cabe duda de que algo de esto hay, obviamente, en las prematuras Memorias y en la Autobiografía de una muchacha de veinticinco, veintiséis años. Y propongo, de entrada, que es esta conflictiva situación de expatriada ${ }^{1}$, la que parece marcar a quien será una mujer siempre nostálgica de algo, siempre ansiosa, insatisfecha; alguien que no se siente aceptada del todo, que siempre quiere más, que por largo tiempo no logra elaborar su duelo. Una escritora que se identifica con compatriotas que se encuentran en peores o parecidas circunstancias: con Heredia, "el cisne peregrino"2, cuyos versos empleados como epígrafe de sus Memorias y repetidos en su Autobiografía, parafrasea muy libremente en los "Apuntes biográficos de la señora Condesa de Merlin", de 1844: "iVenturoso [...] venturoso aquel que no conoce otro sol que el de su patria!" (Avellaneda, 1844/1974, p. 65). ${ }^{3}$ A partir de esta evocación de Heredia, Avellaneda desarrolla un texto sobre Mercedes Santa Cruz -con quien también se identifica- que comienza con esta dramática constatación: "Nada [...] es tan amargo como la expatriación [...]" (Avellaneda, $1844 / 1974$, p. 65), y que en su desarrollo se constituye en larga digresión en torno al desarraigo, y, sobre todo, al espacio de acogida, a la sociedad donde deberá insertarse, a cómo se ven y son tratados los extranjeros lejos de su país. Este es, pues, mi tema. Un tema muy trabajado en estos tiempos de grandes desplazamientos humanos, de constitución de comunidades posmigratorias en los sitios de acogida, de rechazo, de xenofobia, de conflictos culturales de todo tipo. Es desde esta perspectiva que me propongo leer los textos escritos por Avellaneda en relación con su llegada a España.

En su Autobiografía la joven relata a Cepeda que su padre, "en los últimos meses de su vida", deseoso de dejar sus huesos a su tierra natal y temiendo, al mismo tiempo, que en Cuba estallase una rebelión como la de "la isla vecina" -por supuesto, Haití-, había proyectado regresar a Sevilla; plan frustrado por la muerte, que ella se había propuesto continuar (Avellaneda, $1907 / 1989$, p. 143). Por ello, cuando quince años más tarde el padrastro decide instalarse con toda la familia en España, la joven acoge la idea con beneplácito: "Este proyecto me sacó de mi desaliento; deseaba otro cielo, otra tierra, otra existencia" (Avellaneda, $1907 / 1989$, p. 161). Lo deseaba no solo, como escribe, por aquel sueño insatisfecho de su padre, sino también por los conflictos amorosos y familiares de su primera juventud, tema desarrollado tan ampliamente en la Autobiografía, que ocupa casi un tercio de todo el texto. Mas este deseo de vivir en España, no significaría olvido de su país o desdén por él, lo que le aclara a Cepeda tal vez demasiado enfáticamente: "iPerdone usted!; mis lágrimas manchan este papel; no puedo recordar sin emoción aquella noche memorable en que vi por última vez la tierra de Cuba" (Avellaneda, 1907/1989, pp. 163-164); pasaje, por lo demás, muy colocado en la tradición de la tristissima noctis imago de Ovidio (Trist. 1, 3, 1-2, 2002, p. 28), el gran paradigma de la literatura del exilio.

En las Memorias, subtituladas Desde mi salida de Cuba hasta mi llegada a Sevilla, o sean apuntaciones de mis viajes, la descripción del ámbito marítimo alterna con rememoraciones o meditaciones en las 
que el triste destino de la narradora, su destierro, es puesto de relieve. El epígrafe de Heredia con que comienza: "Feliz, Elpino, el que jamás conoce / otro cielo ni sol que el de su patria" (Avellaneda y Arteaga y Figarola-Caneda, 1914, p. 1) -tomado de su poema "A Elpino"-, y los versos de una canción oída cada noche a los tripulantes del velero francés en que viaja -que identifico con parte de la letra de "Ma Normandie", citada de memoria y mal (Avellaneda y Arteaga y Figarola-Caneda, 1914, p. 3)-, condicionan y orientan una lectura nostálgica del texto, del mismo modo que sendos pasajes de Byron: "El corsario" (Avellaneda y Arteaga y Figarola-Caneda, 1914, pp. 2-3), y otra vez de Heredia: "Niágara" (Avellaneda y Arteaga y Figarola-Caneda, 1914, p. 4), también aludidos o citados de memoria, ilustran, respectivamente, las bonanzas y peligros de la navegación, legitiman desde su autoridad literaria la conducta entusiasta o temerosa de la autora, y la 'guían' hacia una aventura desconocida.

\section{2.}

Antes de proseguir diremos que estas Memorias y la Autobiografía, conocidas a partir de su publicación en las primeras décadas del siglo XX -en 1907 la Autobiografía y en 1914 las Memorias-, muestran algunos rasgos comunes.

Ambas fueron escritas en el lapso de unos pocos meses: las Memorias, entre el 7 de noviembre y el 8 de diciembre de 1838; la Autobiografía, del 23 al 27 de julio de 1839; a lo que se debe añadir que una pequeña parte de lo narrado en las primeras se incorpora a la segunda. Por otra parte, se trata en ambos casos de textos privados, escritos para destinatarios explícitos: la prima Heloysa de Arteaga y Loynaz y el amado Ignacio de Cepeda. De modo que, por momentos, las Memorias exhiben un estatuto cercano al de las cartas, percibimos en ellas la presencia de la destinataria: "Si has leído a Montesquieu -le escribe a Heloysa-, si eres, como yo, entusiasta de su genio, tu alma adivinará las emociones que experimentó la mía cuando estuve en Las Bredas" (Avellaneda y Arteaga y Figarola-Caneda, 1914, p. 9). Y, además en las Memorias existen referencias explícitas a la correspondencia sostenida previamente con su prima. Por ejemplo, la autora alude, sin mencionar su nombre, a su desdichado noviazgo con el gallego Ricafort: "aquel sueño fugaz de ventura", y le recuerda a su destinataria lo que ya esta conoce: "Tú sabes de qué hablo" (Avellaneda y Arteaga y Figarola-Caneda, 1914, p. 9). La Autobiografía tiene un carácter indiscutiblemente epistolar, muy estudiado a partir del momento en que comenzó a reconocerse el valor per se de este texto, su mérito autónomo, y no ancilar, no puesto al servicio de una mejor lectura de la obra 'verdaderamente literaria' de Avellaneda. La Autobiografía, o sea, este "cuadernillo" (Avellaneda, 1907/1989, p. 141), que ocupa el segundo lugar cronológico en la edición del epistolario, a continuación de la primera carta, de 13 de julio, muestra clamorosamente los espacios que nos permiten identificar una carta como tal y no como otro tipo de discurso, porque no solo ostenta la fecha o el momento en que se retoma su escritura, ${ }^{4}$ sino que tiene un destinatario al que la autora saluda y al que se dirige de modo enfático; dedica secciones completas a reconvenciones, recapitulaciones y consideraciones generales ubicadas y referidas al hoy de sus relaciones con Cepeda, y cuenta con despedida y posdata, ambas rubricadas con su firma. Pero el carácter epistolar de la Autobiografía no solo se evidencia en elementos formales como los que acabo de indicar, sino sobre todo se pone de manifiesto en una estrategia persuasiva marcada por la asunción de múltiples recursos retóricos, y en el carácter de conversación a distancia que muestra a cada paso y que es característico de una carta. Carta que en este caso, como ambos corresponsales viven en la misma ciudad y frecuentemente se encuentran -o no, iy qué molesta se pone Tula cuando no! (Avellaneda, 1907/1989, p. 153)-, se constituye en ampliación de un diálogo que por ser escrito le permite hacer mayor y mejor uso de la palabra a quien se está formando como escritora, y se ha encargado desde el principio del texto de probar sus saberes y capacidades literarias: no olvidemos que la primera carta de este epistolario incluye un poema, al que su autora le añade una explicación...

Así pues, Memorias y Autobiografía se adscriben tanto al pacto autobiográfico, como al pacto epistolar y obedecen a ambos.

\section{3.}

Por mucho tiempo la tradición filológica no otorgó a cartas, memorias, autobiografía, un estatuto literario propio, sino que las valoró como fuentes o complementos para el acercamiento a distintos estratos del estudio de textos de sus autores, o de hechos relacionados con sus vidas, y aun del período histórico y el entorno en que se produjeron o desarrollaron. Uno de los abordajes más frecuentes, y todavía muy practicado, es el que consiste en tomar estos textos como fuentes documentales para reconstruir aspectos de la vida de sus redactores; otro, el que los emplea como elemento auxiliar para el estudio de su producción li- 
teraria. Y sabemos que esto es lo que ha ocurrido durante casi un siglo con Avellaneda.

La crítica contemporánea, es obvio decirlo, ha otorgado otra dimensión a estas producciones textuales, y ha desarrollado un abundante aparato epistemológico cuyas más sólidas bases se sitúan en la constatación de que las llamadas "escrituras del yo" son construcciones literarias que como tales no constituyen una fuente de verdad objetiva, no son 'the real thing', sino que, por lo contrario, implican a sus autores tanto en un proceso de objetivación, en un verse puestos en papel, como en un construirse para otros y para sí mismos, en un reconocerse fuera de sí, en poder leerse como textualización forzosamente selectiva y manipulada de sus sentimientos y experiencias, textualización inscrita en convenciones y colocada en una tradición formal.

Pero cartas privadas, memorias, autobiografía, también sirven de auxiliar a la investigación histórica. Y es precisamente en este sentido en el que más se aviene la vieja tradición filológica, amante de las llamadas 'fuentes', con los nuevos desarrollos del saber, ya que un estudio de esta producción textual desde esa perspectiva, contribuye en gran medida a la historia de la vida cotidiana, de las mentalidades, a la historia social, a la historia de las mujeres, a la antropología cultural, etcétera.

Y esta es la lectura que me propongo hacer de estos textos. Porque lo que me interesa de ellos, de las Memorias y de la Autobiografía, es precisamente subrayar lo que nos dicen del espacio de recepción de la cubana emigrada, expatriada... Marcar cómo ella lo describe y analiza en estos textos privados, tomando muy en cuenta quiénes son los destinatarios: una prima cubana residente en el Camagüey, y un enamorado español, sevillano; y cuáles son los propósitos de cada texto, para los que selecciona estrategias narrativas y material temático -lo que llamaban los retóricos res-acordes con los fines que persigue y con el molde literario que ha elegido para cada relato.

Ello nos lleva de la mano a las diferencias que distinguen a ambos textos. Las Memorias se ubican en el campo de la literatura de viajes, como lo establece su propio subtítulo. Son una narración comentada, para una destinataria cercana y curiosa, de los espacios recorridos, de las vivencias positivas y negativas experimentadas a lo largo de un periplo bien determinado topográfica y cronológicamente; de modo que se construyen igualmente como un sitio donde compartir recuerdos comunes, recuerdos de familia. La
Autobiografía está colocada explícitamente en el paradigma de lo confesional, pero tiene como finalidad evidente dar una versión de sí misma, la que consideraría más atractiva para el reacio o poco entusiasta galán a quien va dirigida.

\section{4.}

La literatura de viajes del ochocientos exhibe una serie de características generales que no podemos obviar al acercarnos a las Memorias de Avellaneda. Por una parte, y en sentido general, hay que tener en cuenta que nadie viaja a lo ignoto, que el viajero se dirige siempre a un país conocido, imaginado, construido previamente por lecturas y conversaciones; es decir, que todo lo que Tula le escribe a su prima va a tener un doble referente: el de la realidad vivida y el de los libros leídos o las ideas transmitidas por otros acerca de la experiencia del viaje y de los sitios recorridos. De igual modo, ha de recordarse que "el yo que viaja -como se ha dicho- transporta consigo todas las posiciones que ha ocupado [...] está simultáneamente en [distintas] partes, recapitulando a cada instante una totalidad de saberes" (Tamborenea, 1992, p. 309), los cuales se inscriben en el texto como huellas, y en ocasiones como esta, como huellas contrastadas de sus andanzas y sus vivencias anteriores. $Y$ el viajero también transporta consigo las ideas de su tiempo, una cosmovisión que determina su acercamiento y evaluación de 'lo otro', de 'los otros'. En fin, que un libro de viajes, y de un modo explícito esto son sus Memorias, debe leerse como un denso palimpsesto en que se superponen múltiples voces y experiencias.

Por otra parte, no podemos desconocer que la literatura de viajes europea y norteamericana contaba en el siglo XIX con una retórica y una sintaxis narrativa muy elaboradas. De acuerdo con ellas, y mirando siempre las expectativas y las experiencias de lectura de sus destinatarios también europeos y norteamericanos, estos relatos de viaje debían subrayar lo nuevo, lo inédito, el elemento de la aventura, de lo pintoresco; en fin, las novedades, los portentos y la extrañeza de unas tierras desconocidas, exóticas; y no pocas veces, para lograr satisfacer a este público mayormente lector de novelas, el autor debía amoldarse a las exigencias del género narrativo.

En consecuencia, los relatos solían dividirse en dos partes. La primera, en la que se describía el viaje como desplazamiento, tenía a su vez dos subdivisiones: su ámbito marítimo, preñado de tormentas o bendecido por mares y celajes benévolos $y$, por ende, propicio para las meditaciones; y su espacio terrestre, merecedor de que 
el autor se detuviera en la pintura de los primitivos medios de transporte, los inconvenientes de los precarios hoteles y posadas, el mal estado de los caminos y los peligros que podían causar bandidos y animales siempre prestos al ataque. La segunda parte se ocupaba de registrar la novísima realidad observada por el viajero: naturaleza, historia, población -etnias, capas y clases sociales-, comidas, costumbres domésticas, diversiones, cultura, educación, religión... (Campuzano, 1997-1998).

Aunque Avellaneda no se dirige a lo exótico, sino a lo que supone domesticado, o, como diríamos hoy, desarrollado; y viaja porque quiere zambullirse en la civilización, desplazarse del margen colonial al centro metropolitano, la retórica y la sintaxis narrativa de su texto conservan, en buena medida, rasgos de las de los europeos y norteamericanos que en un principio habrían sido indirectamente sus modelos o, mejor, los modelos de su modelo, de aquel que en muchos sentidos fue su paradigma: José María Heredia.

Detengámonos brevemente a ver cómo en la primera de sus "Cartas de los EstadosUnidos", Heredia exhibe la más estricta fidelidad al modelo europeo (Campuzano, 2008, p. 28), el cual se combina, dado el carácter forzoso de su viaje -es un proscrito-, con el modelo ovidiano de la literatura del destierro (GuiIlén, 1998, p. 30). Para empezar, la narración del viaje, la descripción de su proceloso ámbito marítimo; después, la tristeza e inconvenientes de una terra ignota, de un medio hostil y, sobre todo, la exasperante incapacidad de comunicación verbal:

¿Qué decir de la navegación? [...] en la mayor furia de la borrasca me pasaba horas enteras sentado en la popa mirando el mar enfurecido [...] Los vientos contrarios [...] nos han hecho detener en este fondeadero [...] Bajé a tierra, y vi con horror lo que es invierno. Un río estaba ya helado. [...] Ni una hierba pudo consolar la vista de esta aridez espantosa. No se ven ni un hombre, ni un animal, ni un insecto. Los dos únicos edificios en que los ojos pueden descansar, el faro y la posada [...] tienen aspecto de sepulcros [...] Fui al faro, que está al cuidado de un soldado [...] me dijo algunas palabras afectuosas e incomprensibles. [...] no entiendo una sílaba [...]. (Heredia, 1826/1988).

Por otra parte, salvo honrosas excepciones, en la recolección y estudio de la literatura producida por viajeros hispanoamericanos, se ha otorgado escasa importancia a los textos escritos por mujeres, sin reconocer que ha tenido muchas cultivadoras notables en más de un sentido. No obstante, desde hace unas tres décadas, estas memorias, estos diarios, estas car- tas de mujeres que viajan han promovido numerosos abordajes, estimulados por la riqueza y variedad de la información que aportan al conocimiento de la vida cotidiana del país visitado, de la situación de las mujeres que encuentran en sus caminos, e igualmente de ellas mismas y de otras mujeres de sus países de origen. Estos textos proporcionan, igualmente y por múltiples razones, documentación y testimonios del mayor interés a la crítica y a los estudios de género.

\section{5.}

Publicadas en 1914 por Domingo Figarola Caneda y reeditadas posteriormente por su viuda, las Memorias de Gertrudis Gómez de Avellaneda, sus "apuntaciones de [...] viajes", fueron escritas en Sevilla treinta y un meses después de su partida por el puerto de Santiago de Cuba, para que su prima Heloysa Arteaga y Loynaz conociera tanto los detalles de las travesías, como de las ciudades donde había residido o que había visitado. Y para ello la autora le dice -dato interesanteque ha tomado notas en su "libro de Memorias, las que iba haciendo respecto a todo aquello que veía y que juzgaba digno de serte comunicado" (Avellaneda y Arteaga y Figarola-Caneda, 1914, p. 6); es decir, que tenía un diario de viaje o un cuaderno de anotaciones. Pero a continuación le advierte: "No esperes [mucho,] conténtate con una ligera reseña"; y sin dudas está desde el principio consciente del carácter incompleto, no pulido de estas páginas: "Acepta estos borradores tales cuales son, como una memoria de tu fiel amiga" (Avellaneda y Arteaga y Figarola-Caneda, 1914, p. 2).

Las Memorias se organizan en cuatro cuadernillos que ocupan poco más de cuarenta páginas, y que se distribuyen del siguiente modo: el primero, iniciado el 7 de noviembre, narra la travesía desde Santiago de Cuba hasta la llegada a Francia, e incluye la descripción de Burdeos. El segundo, fechado el 12 del propio mes, se ocupa de su larga estancia en Galicia, en La Coruña, y de su partida de esta ciudad y su paso, de camino, por Santiago de Compostela, Pontevedra y Vigo. El tercero, fechado el 29 de noviembre relata el viaje hasta Lisboa y luego el arribo a Cádiz y Sevilla, con las descripciones y consideraciones de rigor. El cuarto cuadernillo, de 8 de diciembre, trata exclusivamente de la descripción de la catedral de Sevilla, y en él anuncia que habrá otro "consagrado a las ruinas de Itálica", así como a Constantina, "cuna de [su] familia" y a "grandiosos edificios" de Sevilla (Avellaneda y Arteaga y Figarola-Caneda, 1914, p. 35). Pero en sus páginas también expresa la posibilidad de no proseguir, lo que de hecho parece haber ocurrido. 
Es innegable la impronta del modelo europeo en su relato de viaje. El esquema se cumple fielmente: se dedica una parte a la narración del viaje como desplazamiento, por mar y por tierra. En su descripción del ámbito marítimo, de factura romántica y tono nostálgico, se mezclan escenas de paz y hermosos paisajes nocturnos con desarrollos procelosos y tormentas que constituyen el telón de fondo sobre el que se proyectan los tristes pensamientos de la autora. Pero la llegada a tierra cambia por completo la tonalidad y el ritmo del relato. En los dieciocho días que pasa en Burdeos, registra y fija en su memoria una nueva realidad y un exaltado estado de ánimo que más de dos años después le describe a su prima con la misma fascinación e ingenuidad con que debe de haber contemplado el curso del río que conduce al puerto fluvial y a la ciudad.

Veamos una primera comparación, figura que se multiplica en su relato:

Yo había visto en [Santiago de] Cuba sus soberbios montes, sus campos vírgenes coronados de palmas y caobas ihabía extendido la vista por sus inmensas sabanas y detenídole en sus ricos plantíos!... Sin embargo, me encantaron las campiñas deliciosas que adornan las márgenes soberbias del Garona (Avellaneda y Arteaga y Figarola-Caneda, 1914, p. 5).

\section{$[\ldots]$}

Atravesando las calles de Bordeaux, miraba con sorpresa y placer a todas partes. iQué vida! iQué gentío! ¡Qué movimiento! La elevación y hermosura de las casas, todas de piedra, me admiraban tanto más cuando era esta la primera ciudad de Europa que veía. (Avellaneda y Arteaga y Figarola-Caneda, 1914, p. 6).

Se interesa por todo lo que se ofrece a su mirada, en especial las gentes que descubre en las calles y en la plaza:

Cada charlatán o buscavida acude a situarse [en su puesto]. A un lado se ve un titiritero, al otro se levanta un teatrillo ambulante. No lejos se encuentra una con su cosmorama [y a su anunciador] gritando a toda fuerza de sus pulmones: "Aquí se ven por tres sueldos las principales ciudades de Europa". Otra voz se oye anunciar dos pulgas que tiran de un coche, y bailan un vals; y por cualquier parte se levantan bonitas tiendecillas de lienzo, en las que las vendedoras ofrecen frutas, dulces, perfumes... (Avellaneda y Arteaga y Figarola-Caneda, 1914, p. 8).

La atraen, como sucederá siempre, las novedades de la tecnología, la modernización: "el celebrado puente del Garona, obra grande y atrevida, como el genio del hombre que la concibió" (Avellaneda y Arteaga y Figarola-Caneda, 1914, p. 7), el "alumbrado público de gas que ilumina [los paseos] donde cada noche tres o cuatro mil personas van a respirar la frescura de la brisa en la estación ardiente del verano" (Avellaneda y Arteaga y Figarola-Caneda, 1914, p. 8).

Y también la deslumbra la vida nocturna de la ciudad; su teatro, los cafés:

Gustóme infinito el teatro principal, que es justamente celebrado como uno de los más bellos edificios de Francia. La sala de espectáculos es muy linda, tiene cinco órdenes de palcos y un lujo extraordinario en los adornos y en el escenario (Avellaneda y Arteaga y Figarola-Caneda, 1914, p. 7).

\section{$[\ldots]$}

Al retirarse del paseo, es costumbre tomar sorbetes en alguno de los magníficos cafés [...], y no he encontrado aún otros tan ricos como los que he tomado allí (Avellaneda y Arteaga y Figarola-Caneda, 1914, p. 8).

Por otra parte, es de relevante importancia su interés por visitar el cercano castillo donde había nacido Montesquieu: ya citamos lo que dice de él a su prima. $Y$ aunque lo que sigue al parecer tuerce el rumbo de estas páginas, quisiera recordar que Montesquieu será un personaje decisivo, no por la magnitud de su presencia sino por la trascendencia de su participación, en la última novela de Avellaneda, escrita y publicada en La Habana, en 1861: El artista barquero, donde finalmente Tula descubre cómo abordar críticamente, en sus distintas variantes, la nostalgia, proyectando su propia curación en Josefina, la joven protagonista, una habanera llevada por su padre francés a MarseIla. Es ella quien narra, plenamente consciente de que pertenece a un ayer cancelado, la historia cubana de la familia. Y en su nueva vida no solo exhibe las huellas de haber sido cubana, sino que parece seguir siéndolo a su modo, un modo hecho de detalles: canta aires populares cubanos, conserva un acento peculiar, cuando quiere obtener algo del padre le habla en español, tiene un perro habanero, una jaca camagüeyana, pájaros tropicales... (Campuzano, 2004).

Las Memorias y en cierta medida la Autobiografía, subrayan la significación, reconocida por ella misma, de su breve estancia en Burdeos, como marca, como referente, como signo que tendrá siempre presente pensemos en su larga estancia, años después, en una casa de retiro espiritual de esta ciudad, tras la muerte de su primer esposo-: 
Cuando recuerdo [...] los días agradables que pasé en Bordeaux, paréceme que ha sido un lisonjero sueño. Es hechicero el trato francés: mi pasión por ellos ha sido justificada y no salí de Bordeaux sin mil pesares de dejarlo, mil esperanzas de volver a verlo y mil gratos recuerdos que aún conserva mi corazón (Avellaneda y Arteaga y Figarola-Caneda, 1914, p. 6).

$Y$ resulta reveladora su temprana evaluación de Burdeos "como la línea que divide mis dos existencias: un intermedio entre los sueños dichosos de mi primera edad y las realidades agitadoras de estos dos últimos años de mi vida" (Avellaneda y Arteaga y Figarola-Caneda, 1914, p. 6).

Si comparamos el espacio que dedica en las Memorias a la descripción de la travesía y a la narración de su llegada a Burdeos y de sus paseos por la ciudad, con el espacio que dedica a los mismos temas en la Autobiografía, vemos cómo, pese a la reducción severa que se produce en el segundo texto, el ámbito romántico, poético, riesgoso de la navegación, que ocupa cuatro páginas en las Memorias, aún merece tres párrafos en la Autobiografía-donde, por cierto, vuelve a citar a Heredia y a Byron-, espacio mucho mayor que el que concede en ella a todo lo relativo a Burdeos: un solo párrafo, en que repite algo de lo escrito en las Memorias: "Los días que pasé en Burdeos me parecen ahora un lisonjero sueño" (Avellaneda, 1907/1989, pp. 164-165); mientras que en lo que escribe para Heloysa lo que relata de la ciudad del Garona ocupa cinco páginas.

Pero mucho más interesante es cómo se reporta en ambos textos lo acontecido en el ámbito gallego, porque este es su verdadero espacio de recepción, no el sitio por donde transita, sino el lugar donde ha de vivir casi dos años. En las Memorias, Galicia, y en especial La Coruña, se trata en diez páginas cargadas de descripciones, narraciones y quejas; y en ellas apenas se hace alusión a su mal terminado noviazgo con Ricafort, cuyo nombre no se menciona, y al destino que él puede haber corrido en la primera guerra carlista. Sin embargo, en la Autobiografía, solo dedica tres páginas y cuarto a La Coruña, en las cuales casi solo se ocupa, nombrándolo varias veces, de Ricafort y su relación. Y solo en un párrafo se refiere a cómo era tratada por el novio y la familia del padrastro dada su otredad, su condición de extraña, de extranjera.

El segundo cuadernillo de las Memorias, centrado, como decíamos, en Galicia, nos ofrece una severa y al parecer bastante objetiva valoración de un entorno nada grato a la autora, pero que al ser contemplado desde la distancia de lo que ya no es experiencia cotidiana, sino transcurso que se rescata del pasado, no deja de conmoverla, sobre todo en lo que toca a la condición femenina y a la miseria de esta periferia, de este verdadero finis terrae adonde ha venido a parar para chocar con una realidad inesperada tanto dentro como fuera de la casa.

Recién llegada del esplendor luminoso de Burdeos, de la circulación de las gentes por las calles, de lo que ha visto o visitado: los distintos espectáculos y diversiones populares, los prodigios de la modernización, los impresionantes espacios de la alta cultura, ya contemporáneos, ya históricos y cargados de prestigio, la estremece la carencia de signos sobresalientes de vida urbana en Galicia: o no existen, o son de pobre factura o calidad, y esto la impresiona no tanto cuando compara La Coruña y otras ciudades gallegas con Burdeos, como cuando recuerda a Puerto Príncipe o a Santiago de Cuba. Su percepción de esta diferencia a través del silencio de las noches citadinas en las que no se oye en las calles el sonido de ningún coche, es una excelente muestra de su sensibilidad para captar la diferencia aun en lo aparentemente menos impresionante:

[...] no habiendo estado yo hasta entonces en población ninguna en que no hubiese carruajes, me parecía especialmente por las noches notar en La Coruña un aire de tristeza y languidez, echando de menos aquel estrepitoso y alegre ruido de los carruajes, a que mi oído estaba acostumbrado (Avellaneda y Arteaga y Figarola-Caneda, 1914, p. 14).

Por otra parte, con esta doble perspectiva comparativa que le imponen la condición cubana de su destinataria y el recuerdo de la ciudad por donde ha pasado antes, describe la miseria que asoma su rostro a cada paso:

A todo americano debe chocarle de una manera muy desagradable la pobreza de Galicia [...] ver por la calle una tropa de mendigos cubiertos de trapos asquerosos sitiar al forastero, importunar y hacer mil bajezas para obtener una moneda de cobre. La misma mendicidad en nuestra Cuba no es tan repugnante con mucho como la de Galicia, y yo no había visto todavía este exceso de miseria y de degradación humana. Padecía mi corazón cada vez que salía a la calle, cada vez que me ponía al balcón, y viniendo de Burdeos, donde no se ve un mendigante, no podía dejar de hacer reflexiones muy dolorosas sobre nuestra metrópoli (Avellaneda y Arteaga y FigarolaCaneda, 1914, p. 13). 
La sorprende "la poca sociabilidad que hay por lo general en el carácter gallego; los chismes, murmuraciones, rivalidades y etiquetas" que hacen imposible el trato. Y a "la pobreza, el desaseo y el abandono" de las capas más desfavorecidas, se une "una ignorancia tan crasa, que no sabré expresar cuánto me sorprendió" (Avellaneda y Arteaga y FigarolaCaneda, 1914, p. 14).

A todo ello agrega la impresión que le causa en Santiago de Compostela la primitiva religiosidad de los fieles, la conservación de multitud de reliquias y su culto, de los que se burla, por su simpleza e idolatría:

Dícese que en una capilla [de la catedral] está el cuerpo del apóstol Santiago, y en la misma se encierran otras muchas reliquias de santos, sobre lo que el fanatismo y la superstición han echado un velo de ridículo que destruye en gran parte el efecto religioso que debiera producir. No se da fácil entrada a los forasteros que van a visitar esta Capilla, pero se les regala un largo papel impreso que contiene la lista de todas las santas preciosidades y reliquias que dicen haber en ella, y no pude menos que reírme leyendo esta enumeración en la que una gota de la leche virginal de María Santísima está en primer lugar (Avellaneda y Arteaga y Figarola-Caneda, 1914, p. 16).

Lo que parece impresionarla más son las obligaciones, el trabajo doméstico de las mujeres, tema que asume desde una perspectiva crítica en que también está explicitada su comparación con las cubanas, una perspectiva que pretende ser objetiva, pero para cuya apreciación la futura autora de Sab -novela abolicionista que posiblemente ya había comenzado a escribir- no toma en cuenta el lado más importante, y sin embargo oculto, oscuro, del asunto; es decir, el hecho de que en Cuba las mujeres de su clase y hasta muchas de capas menos favorecidas, no hacen, no tienen que hacer esos trabajos, porque son otras mujeres, las esclavas, las que los realizan. Cito extensamente lo que escribe, porque será precisamente el tema de los roles femeninos, de las responsabilidades domésticas de la mujer, de su educación, el único que retomará con relación a la vida cotidiana en Galicia en su Autobiografía, narración en la que ocupa el lugar de la víctima, y no el de esta severa y a la vez sorprendida observadora que ahora escucharemos hablar:

Las damas (excepto algunas pocas de la alta aristocracia [...]) acostumbran planchar sus vestidos ellas mismas, calcetan, guisan si se ofrece, y se emplean en casa en otras mil faenas que una señora en mi país miraría como degradantes, y que ni soñando jamás podré hacer. Por eso las americanas pasamos en Galicia por perezosas, holgazanas y poco aptas para el gobierno doméstico; y yo creo que es innegable que bien por el efecto del clima, bien por la educación, somos en realidad las cubanas por lo menos, más indolentes que las gallegas, y que rara mujer en nuestro país se sometería con gusto a ahumarse por la mañana en la cocina, y a pasar la noche con la calceta en la mano (Avellaneda y Arteaga y Figarola-Caneda, 1914, pp. 14-15).

Y no puedo dejar de añadir a estas, otras palabras suyas mucho más justas y acordes con la realidad: "En la clase del pueblo he admirado en las mujeres de Galicia un vigor y fortaleza que resiste a los trabajos más duros, y al parecer más impropios del sexo" (Avellaneda y Arteaga y Figarola-Caneda, 1914, p. 15).

Pasemos, pues, a la Autobiografía de Tula, donde ella es por definición el gran tema, la materia del texto, Autobiografía en la que desarrolla con los más enfáticos registros de la persuasión, la agonía de su enfrentamiento personal con la Galicia profunda representada por quienes han estado más cerca de ella: el padrastro, que aunque "se había manejado bien con nosotros hasta entonces: entonces se desenmascaró. Estaba en su país y con su familia, nosotros lo habíamos abandonado todo. Su alma mezquina abusó de estas ventajas" (Avellaneda, 1907/1989 p. 165). Y, representada sobre todo, en aquella falta de sociabilidad y en la ignorancia de las que hablara en las $\mathrm{Me-}$ morias, por las parientas del padrastro y por el novio. Las primeras ni la comprenden ni la aceptan: "Decían que yo era atea, y la prueba que daban era que leía las obras de Rousseau y que me habían visto comer con manteca un viernes [...]" (Avellaneda, 2003, p. 163).

Pero nos damos cuenta de inmediato de que la joven lectora del Emilio comprende solo en parte -pues como ya advertimos, nunca ve el carácter determinante de la esclavitud en las Antillas, no está entrenada para ello, sino todo lo contrario- por qué las parientas de su padrastro piensan así, y aventura una causa plausible de su incapacidad para entenderla:

La educación que se les da en Cuba a las señoritas difiere tanto de la que se les da en Galicia, que una mujer, aun de la clase media, creería degradarse en mi país ejercitándose en cosas que en Galicia miran las más encopetadas como una obligación de su sexo. Las parientas de mi padrastro decían, por tanto, que yo no era buena para nada, porque no sabía planchar, ni cocinar, ni calcetar, porque no lavaba los cristales, ni hacía la cama, ni barría mi cuarto. Según ellas yo 
necesitaba veinte criadas y me daba el tono de una princesa. Ridiculizaban también mi afición al estudio y me llamaban la Doctora. (Avellaneda, 1914, p. 28).

Mas, cuidado: si tomamos en cuenta que desde tiempos de la restitución de Fernando VII, "ateos y russonianos", así como "afrancesados, liberales, masones, volterianos", fueron epítetos empleados contra los defensores de una nueva España, de una España constitucional, y que estas acusaciones bastaban para conducirlos al destierro (Zavala, 1989, XXXV, p. 24), no dejan de ser peligrosos, en los momentos más enconados de la primera guerra carlista, los términos - literales o fraguados por ella- en que la joven Tula transcribe el desprecio de la familia de Escalada por la joven que nunca había tolerado a su padrastro, y que ahora también padecía por la infelicidad y los pesares de su madre (Avellaneda, 2003, p. 161).

Ricafort, el novio gallego con quien tal vez hubiera llegado a casarse, era "inferior en talento" a ella, dice,

[...] y parecía humillado de la superioridad que me atribuía; sus ideas y sus inclinaciones contrariaban siempre las mías. No gustaba de mi afición al estudio y era para él un delito que hiciese versos. Mis ideas sobre muchas cosas le daban pena e inquietud. Temblaba de la opinión ${ }^{5}$ y decíame muchas veces: “-¿Qué lograrás cuando consigas crédito literario y reputación de ingenio? Atraerte la envidia y excitar calumnias y murmuraciones" (Avellaneda, 2003, p. 161).

Tendríamos mucho más que hacer y decir. Habría que revisar por ejemplo, los censos, la historia de la vida privada, de la familia, de las mujeres en la Galicia de la primera mitad del siglo XIX; habría que estudiar, casi, o sin casi, comenzar a estudiar las mentalidades, los textos familiares de las cubanas dueñas de esclavos; habría que hurgar más, o simplemente hurgar en la condición femenina en los espacios coloniales... Hasta que eso no se haga, y no es labor de una sola persona, ni siquiera de una docena de ellas, no estará verdaderamente concluido este acercamiento al choque de la joven Tula con su espacio de recepción, tan idealizado por ella desde Cuba.

Pero algo tenemos que decir para terminar. Por una parte, que la descripción que ofrece Avellaneda de su situación en el lugar de acogida, en Galicia, no solo da cuenta, en sentido general, de lo pautado en torno a la dinámica de la exclusión/inclusión femenina en relación con el espacio público, sino muy particularmente de las paradojas, contradicciones y ambigüedades de la condición de las mujeres de clase media y alta del mundo colonial, en compara- ción con las mujeres de iguales capas sociales de la periferia metropolitana.

Por otra parte, que tanto las Memorias como la $\mathrm{Au}$ tobiografía, muestran el desvanecimiento de su viejo sueño de viajar a España, asociado a la influyente memoria de su padre, desvanecimiento que va experimentando a lo largo de los casi dos años en que reside en Galicia. Memorias y Autobiografía revelan con mayor o menor intensidad, las dificultades con que tiene que enfrentarse, las adversidades y los prejuicios contra los que debería luchar en esa sociedad gallega premoderna en la que el espacio y los roles impuestos a las mujeres estaban muy netamente trazados.

Resulta, en fin, evidente que su encuentro con Galicia no pudo ser más definitorio para ella, porque sin dudas fue allí, comparando el humilde, pacato y hasta miserable tren de vida de sus ciudades con el de las ricas villas de la Isla, constatando la condición de la mujer gallega, su encasillamiento en las tareas domésticas, su beatería y su ausencia total de libertad; recibiendo, a causa de sus intereses y ambiciones literarias, y de su independencia de pensamiento, las más inesperadas censuras de un enamorado asustadizo y de las beatas parientas de su padrastro, teniendo que trasladarse a Andalucía para poder sentirse libre, donde comienza a descubrir y a construir, en su diferencia, en su extrañeza, su condición de mujer 'otra', de cubana y de escritora, y donde empieza a diseñar su autoimagen, a pensar el móvil estatuto, la identidad de fronteras, el nombre con que se imagina y con el que quiere ser conocida: "La Peregrina".

Con este nombre, aplicado "a quien anda por tierras extranjeras", "a las aves de paso", "a animales, plantas, costumbres, etc., que proceden de un país extraño" (Moliner, 1986, s.v. Peregrino), firma Avellaneda los poemas que empieza a publicar en 1838 en la prensa andaluza, después de ganar su independencia económica y de mudarse a Sevilla con su hermano Manuel.

Allí aprenderá también otras cosas, comenzará a alejarse de ciertas costumbres cubanas, y descubrirá sus torpezas. Por eso le escribe a Heloysa esta confesión que no quiero dejar de citar:

[...] no estando habituada, como tú sabes, a andar a pie, me cansaba al momento, no tardaba en rendirme totalmente en medio de la más lucida tarde de paseo, teniendo [...] que sentarme, o volver a casa, maldiciendo de todo corazón la malvada costumbre de pasear a pie. ¿'Te confesaré que en el día [de hoy, el hoy de Sevilla] pienso de un modo opuesto? ... ha- 
bituada ya a estos paseos que gustan cien veces más que los nuestros que me parecen verdaderamente harto sosos y cansados. En efecto, ir sin hablar con los demás paseantes, cada pareja metida en su carruaje, siempre en la misma posición, y sin otro interés u objeto que lucirse, es cosa bien fastidiosa (Avellaneda, 1914, p. 13).

Sin embargo, la nostalgia no irá amainando hasta mucho después. En los primeros tiempos es pura emotividad:

¡Que no estuviera yo ahora sentada en la puerta de tu casa, amada prima, en una de aquellas noches hermoseadas con la luna apacible de nuestra cara patria; a tu lado, en una pequeña y escogida reunión de amigos, rodeadas de tus amables hermanas, y mirando a nuestras dos madres gozar con entusiasmo maternal de nuestros juegos o conversaciones, y refiriéndose, con aquella confianza de una amistad de cuarenta años sus pequeños negocios domésticos!... [...] Yo salí llena de ilusiones a ver mundo... ya he visto bastante, pues he perdido todas mis ilusiones. (Avellaneda y Arteaga y Figarola-Caneda, 1914, p. 10).
La nostalgia se tamizará con el análisis, se convertirá en reflexión, dolorosa, cruda, realista, vivida, revivida, cotidiana. Y se traducirá en resignada aceptación del espacio entre-lugares, del in-between del emigrante, del expatriado, que es también un espacio sin pasado, sin conexiones temporales, como lo expresa muy sobria, muy severamente en las páginas que escribe para la Revista de Madrid en 1844, ocho años después de sullegada, en sus "Apuntes biográficos de la señora condesa de Merlin", que servirán de prólogo al Viaje a La Habana, de Mercedes Santa Cruz:

¿Qué pedirá el extranjero a aquella nueva sociedad, a la que llega sin ser llamado, y en la que nada encuentra que le recuerde una felicidad pasada, ni le presagie un placer futuro? ¿Cómo vivirá el corazón en aquella atmósfera sin amor?

Existencia sin comienzo, espectáculo sin interés, detrás de sí unos días que nada tienen que ver con lo presente, delante otros que no encuentran apoyo en lo pasado, los recuerdos y las esperanzas divididos por un abismo: tal es la suerte del desterrado (Avellaneda, 1974, p. 65).

\section{NOTAS}

1 Utilizo el término con el sentido que tendrá más adelante, el que le da Mary MacCarthy al aplicarlo a poetas ingleses o escritores norteamericanos que se instalan voluntariamente en Europa (Kaplan, 1996, p. 106).

2 Así lo llamará poco después en su elegía "A la muerte del célebre poeta cubano

\section{BIBLIOGRAFÍA}

Anzaldúa, G. (1987). Borderlands / La frontera. San Francisco: Aunt Lute Books.

Campuzano Sentí, L. (1997-1998). Viajeros hispanoamericanos del siglo XIX - Vías de acceso. Terceira Margem. Revista da PósGraduação em Letras da UFRJ, 5-6, pp. 67-74.

Campuzano Sentí, L. (2004). Ruinas y paisajes de la memoria. En Campuzano Sentí, L. Las muchachas de La Habana no tienen temor de Dios. Escritoras cubanas (siglos XVIII al XXI). La Habana: Ediciones Unión, pp. 46-57
Don José María de Heredia" (Avellaneda, 1841/1869, pp. 65-67).

3 He actualizado la ortografía de los textos de Avellaneda.

4 Ello también permite a algunos autores relacionar la Autobiografía con un diario, dotando a su estatuto genérico de mayor ambigüedad e hibridismo.
Campuzano Sentí, L. (2008). Tristes tropicales: exilio y mitos clásicos en poetas cubanas de la diáspora. La Gaceta de Cuba, 6, pp. 27-32.

Freud, S. (1915/1976). Duelo y melancolía. En Obras completas. Buenos Aires: Amorrortu, (vol. XIV), pp. 235-255.

Gómez de Avellaneda, G. (1869). Obras literarias. Poesías líricas (vol. I). Madrid: Imprenta y Estereotipia de M. Rivadeneyra.

Gómez de Avellaneda y Arteaga, G. y Figarola-Caneda, D. (1914). Memorias
5 Recordemos lo que decía en las Memorias de los "chismes, murmuraciones, rivalidades y etiquetas" de los gallegos.

inéditas de la Avellaneda. La Habana: Imprenta de la Biblioteca Nacional.

Gómez de Avellaneda, G. (1844/1974). Apuntes biográficos de la señora Condesa de Merlin. En Santa Cruz y Montalvo, M. (Condesa de Merlin). Viaje a La Habana. La Habana: Instituto Cubano del Libro, pp. 61-74.

Gómez de Avellaneda, G. (1907/1989). Autobiografía. En Catena, E. (ed.) Poesías y epistolario de amor y de amistad. Madrid: Castalia, pp. 137179. 
Guillén, C. (1998). El sol de los desterrados: literatura y exilio. En Múltiples moradas. Barcelona: Tusquets, pp. 29-97.

Hall, S. (1987). Minimal Selves. The Real Me. Post-Modernism and the Question of Identity. Londres: ICA Documents 6, pp. 44-46.

Heredia, J. M. (1826/1988). Cartas de los Estados Unidos. México: Universidad
Nacional Autónoma de México (vol. II), pp. 100-102.

Kaplan, C. (1996). Questions of Travel. Postmodern Discourses of Displacement. Durham y Londres: Duke University Press. http://dx.doi. org/10.1215/9780822382041

Moliner, M. (1986). Diccionario de uso del español. Madrid: Gredos.
Ovidio (2002). Tristes. Cartas del Ponto. Madrid: Alianza.

Said, E. W. (1984). Reflections on Exile. Granta, 13, pp. 157-172.

Tamborenea, M. (1992). La constitución de la subjetividad en los relatos de viaje de los '80. Dispositio, XVII, 42-43, pp. 307-321. 